\title{
UVEITOGENIC PROTEINS ISOLATED FROM BOVINE IRIS AND CILIARY BODY
}

\author{
SCOTT C. SIMPSON, HENRY J. KAPLAN and NALINI S. BORA \\ St Louis, Missouri
}

\begin{abstract}
SUMMARY
Experimental autoimmune anterior uveitis (EAAU) is an animal model for acute anterior uveitis in humans. Previously, we have shown that EAAU can be induced in Lewis rats by a protein(s) associated with ocular melanin. The present study was designed to further purify the pathogenic antigen. Melanin associated antigen (MAA), isolated from bovine iris and ciliary body, was digested with V8 protease and the soluble protein separated on a cation exchange column. The bound protein was eluted with a salt gradient. Lewis rats were immunised with the resulting fractions to test for pathogenicity. Moderate to severe EAAU, with clinical and histopathological features similar to induction with crude soluble bovine MAA, was observed with the 100-200 $\mathrm{mM}$ gradient of $\mathrm{NH}_{4} \mathrm{Cl}$. Thus, bovine MAA has been partially purified using cation exchange chromatography. Studies are currently under way to purify bovine MAA to homogeneity.
\end{abstract}

Acute anterior uveitis (AAU) is a common form of intraocular inflammation of unknown aetiology that presents with either iritis and/or iridocyclitis, with a spillover of inflammatory cells into anterior vitreous. Retinitis is not a component of anterior uveitis. ${ }^{1}$ Experimental autoimmune anterior uveitis (EAAU) is an organ-specific autoimmune disease and serves as a model of human acute anterior uveitis. ${ }^{2-9} \mathrm{We}$ and others have shown that EAAU can be induced in Lewis rats by a single injection of insoluble bovine melanin associated antigen (MAA) isolated from the retinal pigment epithelium or uvea. ${ }^{2-9}$ We have also reported that a uveitogenic protein antigen(s) can be solubilised and cleaved from uveal melanin by proteolytic enzyme treatment using $\mathrm{V} 8$ protease. The enzyme-digested soluble fraction contains about

From: Department of Ophthalmology and Visual Sciences, Washington University School of Medicine, St Louis, MO 63110, USA.

Correspondence to: Nalini S. Bora, PhD, Department of Ophthalmology and Visual Sciences, Box 8096, Washington University School of Medicine, 660 South Euclid, St Louis, MO 63110, USA. Tel: +1(314) 362-1665. Fax: +1(314) 362-3638.
20 well-resolved protein bands, as revealed by SDSPAGE analysis, and is uveitogenic. ${ }^{8}$ The present study was undertaken to further purify the pathogenic antigen in EAAU.

\section{MATERIALS AND METHODS}

Animals

Pathogen-free male Lewis rats were purchased from Harlan Sprague Dawley (Indianapolis, IN). The animal protocol conformed to the ARVO resolution on the use of animals in research.

\section{Reagents}

Purified pertussis toxin (PTX), Triton X-100, CMsepharose and Staphylococcus aureus V8 protease were obtained from Sigma (St Louis, MO), complete Freund's adjuvant (CFA) from Difco (Detroit, MI).

\section{Antigen}

MAA was prepared by modification of the method originally described by Broekhuyse $e t$ al. ${ }^{2.3}$ Pigmented eyes were obtained from freshly killed cows and the iris/ciliary body carefully separated from the remaining ocular tissue. The iris and ciliary body were subjected to buffer extraction by briefly homogenising with minimal amounts of phosphatebuffered saline (PBS) pH 7.2; the homogenate was filtered through a wire mesh and spun at $1.2 \times 10^{4} \mathrm{~g}$ for $10 \mathrm{~min}$ at $4{ }^{\circ} \mathrm{C}$. The pellet was washed three times with PBS and subjected to detergent extraction using $2 \%$ Triton X-100 at room temperature for $3 \mathrm{~h}$. The reaction mixture was spun at $1.2 \times 10^{4} \mathrm{~g}$ for $10 \mathrm{~min}$ at $4{ }^{\circ} \mathrm{C}$ and the pellet containing MAA was washed first with PBS, then with water, lyophilised and stored at $-20{ }^{\circ} \mathrm{C}$.

\section{Proteolytic Enzyme Treatment}

Four grams of MAA was digested with 4000 units of Staphylococcus aureus V8 protease as previously described by us. ${ }^{8}$ After digestion with V8 protease samples were centrifuged at $1.2 \times 10^{4} \mathrm{~g}$ for $15 \mathrm{~min}$ at 
$4{ }^{\circ} \mathrm{C}$ and then at $2.7 \times 10^{4} \mathrm{~g}$ for $15 \mathrm{~min}$. The supernatant was collected, desalted into $100 \mathrm{mM}$ amonium bicarbonate using P6DG desalting columns (Bio-Rad), lyophilised, and redissolved in $\mathrm{N}$-morpholinoethane sulphonic acid (MES) buffer pH 6.0 containing $10 \mathrm{mM} \mathrm{NH}_{4} \mathrm{Cl}$. Protein concentration in these samples was determined following the method of Lowry et al. ${ }^{10}$

\section{Cation Exchange Chromatography}

CM-sepharose was used to prepare a cation exchange column $(2.5 \times 10 \mathrm{~cm})$. The column was equilibrated with $10 \mathrm{mM}$ MES- $\mathrm{NH}_{4} \mathrm{Cl}$ buffer $\mathrm{pH}$ 6.0, and soluble bovine MAA was applied on this column. Bound proteins were eluted with a salt gradient using $10-500 \mathrm{mM} \mathrm{NH}_{4} \mathrm{Cl}$ in $10 \mathrm{mM}$ MES buffer $\mathrm{pH}$ 6.0. The resulting fractions were concentrated by lyophilisation, then desalted and lyophilised again. Animals were immunised with each fraction. Protein concentration was determined prior to immunisation. ${ }^{10}$

\section{Immunisation and Assessment of EAAU}

Male Lewis rats were immunised with the antigen using a single dose induction protocol in the hind footpad. One hundred microlitres of stable emulsion containing various amounts of the antigen was used to immunise the animals and was prepared by mixing equal volumes of CFA and the antigen. Purified PTX at a concentration of $1 \mu \mathrm{g}$ per animal was used as an additional adjuvant. Control animals were injected with the mixture of CFA and PTX only.

The rats were clinically examined starting from day 10 post-immunisation using slit lamp biomicroscopy. Uveitis was graded in a masked fashion using criteria previously reported. ${ }^{2.3}$ The experiments were terminated 30 days after immunisation. Eyes were harvested at various time points for histological analysis to assess the course and severity of the inflammation. The intensity of uveitis (iritis) was scored in a masked fashion on the arbitrary scale of $0-4$ as previously described. ${ }^{8}$ The minimal criterion for scoring an animal as positive by histopathology was the presence of inflammatory cell infiltration of the iris, ciliary body and anterior chamber.

\section{RESULTS}

Proteins were eluted with a $10-500 \mathrm{mM}$ gradient of $\mathrm{NH}_{4} \mathrm{Cl}$ and divided into fractions $1(10-100 \mathrm{mM}$ $\left.\mathrm{NH}_{4} \mathrm{Cl}\right), 2\left(100-200 \mathrm{mM} \mathrm{NH}_{4} \mathrm{Cl}\right)$ and $3(200-350 \mathrm{mM}$ $\mathrm{NH}_{4} \mathrm{Cl}$ ). Each fraction was used to immunise male Lewis rats. Seventy-five micrograms of the antigen, mixed with CFA and PTX, was injected into a hind footpad using a single dose induction protocol. All antigen fractions were pathogenic in recipient Lewis rats (Table I), and the disease (EAAU) caused by these fractions resembled AAU in humans. However, fraction 2, eluted with $100-200 \mathrm{mM} \mathrm{NH}_{4} \mathrm{Cl}$, was most pathogenic as it induced moderate to severe disease bilaterally, in all animals, with the day of onset around day 10-12 post-immunisation (Table I). Fractions eluted with $10-100$ and $200-350 \mathrm{mM}$ $\mathrm{NH}_{4} \mathrm{Cl}$. were less pathogenic. Animals immunised with these fractions developed only mild disease with delayed onset (Table I). Control animals injected with a mixture of CFA and PTX only did not develop disease (not shown).

The clinical pattern of uveitis observed in the animals immunised with fraction 2 was similar to that observed in the animals immunised with crude soluble antigen. Acute iridocyclitis developed around day 10-12 post-injection. Maximum inflammation occurred between days 12 and 14 , and by day 20 disease was subsiding and only mild inflammation was noted. Mononuclear cells started to infiltrate the centre of the ciliary body stroma, with a few cells in the iris and anterior chamber, on day 10-12 postimmunisation. In the severe stage of disease the ciliary body and iris became swollen and heavily infiltrated with inflammatory cells, which were mainly mononuclear cells, with only very few polymorphonuclear cells seen (Fig. 1). An exudate of proteinaceous material with inflammatory cells appeared in the anterior chamber, with cellular precipitates on the corneal endothelium and lens surface, and spill-over into the anterior vitreous. The posterior segment of the eye was minimally affected, with only a mild choroiditis. No inflammation was observed in the cornea or retina.

\section{DISCUSSION}

Human acute anterior uveitis (AAU) is a common form of intraocular inflammation. We, and others,

Table I. Induction of EAAU in Lewis rats by the proteins eluted from a CM-sepharose column

\begin{tabular}{|c|c|c|c|c|c|c|}
\hline \multirow[b]{2}{*}{ Peak no. } & \multirow{2}{*}{$\begin{array}{l}\mathrm{NH}_{4} \mathrm{Cl} \text { conc. } \\
\quad(\mathrm{mM})\end{array}$} & \multirow{2}{*}{$\begin{array}{l}\text { Antigen dose } \\
(\mu \mathrm{g})\end{array}$} & \multicolumn{3}{|c|}{ Eyes with EAAU } & \multirow[b]{2}{*}{ Day of onset ${ }^{\mathrm{a}}$} \\
\hline & & & Incidence & Mild & Severe & \\
\hline 1 & $10-100$ & 75 & $2 / 6$ & 2 & - & $17 \pm 2$ \\
\hline 2 & $100-200$ & 75 & $10 / 10$ & - & 10 & $11 \pm 1$ \\
\hline 3 & $200-350$ & 75 & $1 / 6$ & 1 & - & 24 \\
\hline
\end{tabular}

Incidence of EAAU given as positive/total eyes following clinical examination.

Severity of inflammation on histopathological examination was grouped as mild $(1+$ to $2+)$ or severe $(3+$ to $4+)$.

${ }^{\mathrm{a}}$ Mean \pm standard deviation. 




Fig. 1. Severe EAAU induced by immunisation of Lewis rats with proteins eluted from CM-sepharose column with 100-200 $\mathrm{mM} \mathrm{NH}_{4} \mathrm{Cl}$. At the peak of inflammation severe iritis is present. The anterior chamber and iris is infiltrated by inflammatory cells with dense protein aggregation in the anterior chamber. The ciliary body is also severely inflamed, but not the retina. Sections were stained with haematoxylin and eosin. Original magnification $\times 200$.

have recently developed a clinically relevant animal model of anterior uveitis which is called experimental autoimmune anterior uveitis (EAAU). ${ }^{2-9}$ Essential features of the disease have been reproduced in the Lewis rat by immunisation with the insoluble bovine melanin associated antigen (MAA), as well as by the soluble proteins released by treatment of insoluble bovine MAA with V8 protease. ${ }^{8}$ Since the V8digested soluble fraction revealed the presence of at least 20 different protein bands on SDS-PAGE analysis, the present study was undertaken to further purify the putative pathogenic antigen(s).

Melanin isolated from bovine iris and ciliary body was subjected to proteolytic enzyme treatment using V8 protease to cleave and solubilise uveitogenic proteins. Soluble pathogenic proteins were further fractionated on a cation exchange column using CMsepharose. A salt gradient using $10-500 \mathrm{mM} \mathrm{NH}_{4} \mathrm{Cl}$ was used to elute the bound proteins. Proteins eluted with $100-200 \mathrm{mM}$ salt were highly pathogenic in Lewis rats as assessed by clinical examination and histopathological analysis. Clinical and histopathological features observed in these animals resembled those reported previously. ${ }^{2-9}$ However, this fraction was not a homogeneous preparation as it contained more than one protein band. Efforts are currently being made to further purify these proteins using preparative PAGE.
Thus, our results demonstrate that bovine MAA has been partially purified using cation exchange chromatography. Studies on the further purification and characterisation of the pathogenic antigen(s) are under way in our laboratory.

This work was supported in part by grants from Research to Prevent Blindness, Inc., N.Y., and NIH grants EY10543, EY09730 and EY02687.

Key words: Experimental autoimmune anterior uveitis (EAAU), Melanin, Melanin associated protein, Iris, Ciliary body, Lewis rat.

\section{REFERENCES}

1. Nussenblatt RB, Palestine AG. Uveitis: fundamentals and clinical practice. Chicago: Year Book, 1989.

2. Broekhuyse RM, Kuhlman ED, Winḳens HJ, Van Vugt AHM. Experimental autoimmune anterior uveitis (EAAU), a new form of experimental uveitis. I. Induction by a detergent-insoluble, intrinsic protein fraction of the retina pigment epithelium. Exp Eye Res 1991;52:465-74.

3. Broekhuyse RM, Kuhlman ED, Winkens HJ. Experimental autoimmune anterior uveitis (EAAU). II. Dose-dependent induction and adoptive transfer using a melanin-bound antigen of the retinal pigment epithelium. Exp Eye Res 1992;55:401-11.

4. Broekhuyse RM, Kuhlman ED, Winkens HJ. Experimental autoimmune anterior uveitis (EAAU). III. Induction by immunization with purified uveal and skin melanins. Exp Eye Res 1993;56:575-83.

5. Broekhuyse RM, Kuhlman ED. Experimental autoimmune anterior uveitis: the preparation of uveitogenic ocular melanin. Invest Ophthalmol Vis Sci 1993; 34:698-700

6. Broekhuyse RM, Kuhlman ED, Winkens HJ. Experimental autoimmune anterior uveitis (EAAU): induction by melanin antigen and suppression by various treatments. Pigment Cell Res 1993;6:1-6.

7. Chan CC, Hikita N, Dastgheib K, Whitcup SM, Gery I, Nussenblatt RB. Experimental melanin-protein induced uveitis in the Lewis rat: immunopathogenic process. Ophthalmology 1994;101:1275-80.

8. Bora NS, Kim MC, Kabeer NH, Simpson SC, Tandhasetti MT, Cirrito TP, et al. Experimental autoimmune anterior uveitis (EAAU): induction with melanin associated antigen from the iris and ciliary body. Invest Ophthalmol Vis Sci 1995;36:1056-66.

9. Kim MC, Kabeer NH, Tandhasetti MT, Kaplan HJ, Bora NS. Immunohistochemical studies on melanin associated antigen (MAA) induced experimental autoimmune anterior uveitis (EAAU). Curr Eye Res 1995; $14: 703-10$.

10. Lowry $\mathrm{OH}$, Rosebrough NJ, Farr AL, Randall RJ. Protein measurement with the Folin-Phenol reagent. J Biol Chem 1951;193:265-75. 